\title{
INTEGRATING LIFESPAN DEVELOPMENT THEORIES
}

\section{Implications for the Study of Age(ing) and Work}

\author{
Rachel S. Rauvola and Cort W. Rudolph
}

Researchers studying the aging workforce often draw upon the lifespan development literature, in some form or another, in designing and interpreting their work (see Table 7.1). This is especially true of studies concerning how workers maintain (or even show improvements in) well-being and functioning as they age. Theoretical abundance in this literature bears advantages, providing authors with their choice of mechanisms, systems, and structures to contextualize and test in age or aging research. However, the theories have a great deal in common, and this fact is often disregarded or goes undiscussed in the literature; that is to say, variety does not always translate into uniqueness and differentiation, particularly when applied to the same, specific context (e.g., the workplace).

The purpose of this chapter is threefold. First, we introduce a novel conceptual integration between and extension of lifespan theories, organized in terms of mechanisms, predictions, and guiding principles. Second, we delve into the hallmark characteristics of lifespan development theories in the work and aging literature, placing particular focus on convergent theoretical components. Third, we discuss how our integration can be applied and how applications to the work context can mutually inform and benefit lifespan theories.

\section{Proposed Lifespan Theory Integration}

Our integration focuses on mechanisms, predictions, and guiding principles derived broadly from the lifespan perspective and how their mutual consideration can be used to improve understanding of age(ing) and work. This is not meant to be a new theory, per se. Instead, we treat this integration as a broader operating framework and structure- a set of fundamental assumptions and attributes of "lifespan thinking" - upon which each theory is built and from which future 
TABLE 7.1 Overview of Lifespan Development Theories: Mechanisms and Key References

\begin{tabular}{|c|c|c|}
\hline Theory & Focal Mechanisms & Key References and Measurement Scales \\
\hline $\begin{array}{l}\text { Dual-process model of assimilative and } \\
\text { accommodative coping }\end{array}$ & Tenacious goal pursuit, flexible goal adjustment & $\begin{array}{l}\text { Theory: Brandtstädter and Renner (1990) } \\
\text { Measurement: TEN and FLEX scales from } \\
\text { Brandtstädter and Renner (1990) }\end{array}$ \\
\hline $\begin{array}{l}\text { Model of selection, optimization, and } \\
\text { compensation }\end{array}$ & $\begin{array}{l}\text { Elective selection, loss-based selection, } \\
\text { optimization, compensation }\end{array}$ & $\begin{array}{l}\text { Theory: Baltes and Baltes (1990) } \\
\text { Measurement: SOC scale from Baltes et al. } \\
\text { (1999) }\end{array}$ \\
\hline Motivational theory of lifespan development & $\begin{array}{l}\text { Optimization, selective primary control, selective } \\
\text { secondary control, compensatory primary } \\
\text { control, compensatory secondary control }\end{array}$ & $\begin{array}{l}\text { Theory: Heckhausen et al. (2010) } \\
\text { Measurement: Optimization of Primary and } \\
\text { Secondary Control scales from Heckhausen } \\
\text { et al. (1998) }\end{array}$ \\
\hline Socioemotional selectivity theory & $\begin{array}{l}\text { Future time perspective (focus on opportunities, } \\
\text { limitations; perceived remaining time) }\end{array}$ & $\begin{array}{l}\text { Theory: Carstensen (1991) } \\
\text { Measurement: Future Time Perspective scale } \\
\text { from Carstensen and Lang (1996) }\end{array}$ \\
\hline Strength and vulnerability integration model & $\begin{array}{l}\text { Regulatory strengths and vulnerabilities as they } \\
\text { relate to emotion regulation and health }\end{array}$ & $\begin{array}{l}\text { Theory: Charles (2010) } \\
\text { Measurement: N/A }\end{array}$ \\
\hline $\begin{array}{l}\text { Model of selection, optimization, and } \\
\text { compensation with emotion regulation }\end{array}$ & $\begin{array}{l}\text { Selection, optimization, and compensation in } \\
\text { regulating exposure and responses to affective } \\
\text { events }\end{array}$ & $\begin{array}{l}\text { Theory: Urry and Gross (2010) } \\
\text { Measurement: N/A }\end{array}$ \\
\hline
\end{tabular}


research can draw in selecting constructs, forming predictions, and interpreting findings. Through more integrative thinking, knowledge of age(ing) and work can become more interpretable, unified, and useful.

The three sections of our operating framework - lifespan mechanisms, predictions, and guiding principles (see Figure 7.1) — are explored in the following sections. These three categories are interrelated yet represent distinct contributions of the lifespan literature to understanding motivation, functioning, and development in context.

\section{Mechanisms}

The first, most granular section of our model concerns the theoretical mechanisms that overlap across the covered lifespan theories. The construct space covered by lifespan theories is concentrated: Each theory's mechanisms fall into one of three broader groupings. Specifically, each theory has some representation of (1) goal engagement and disengagement (including goal selection, commitment,

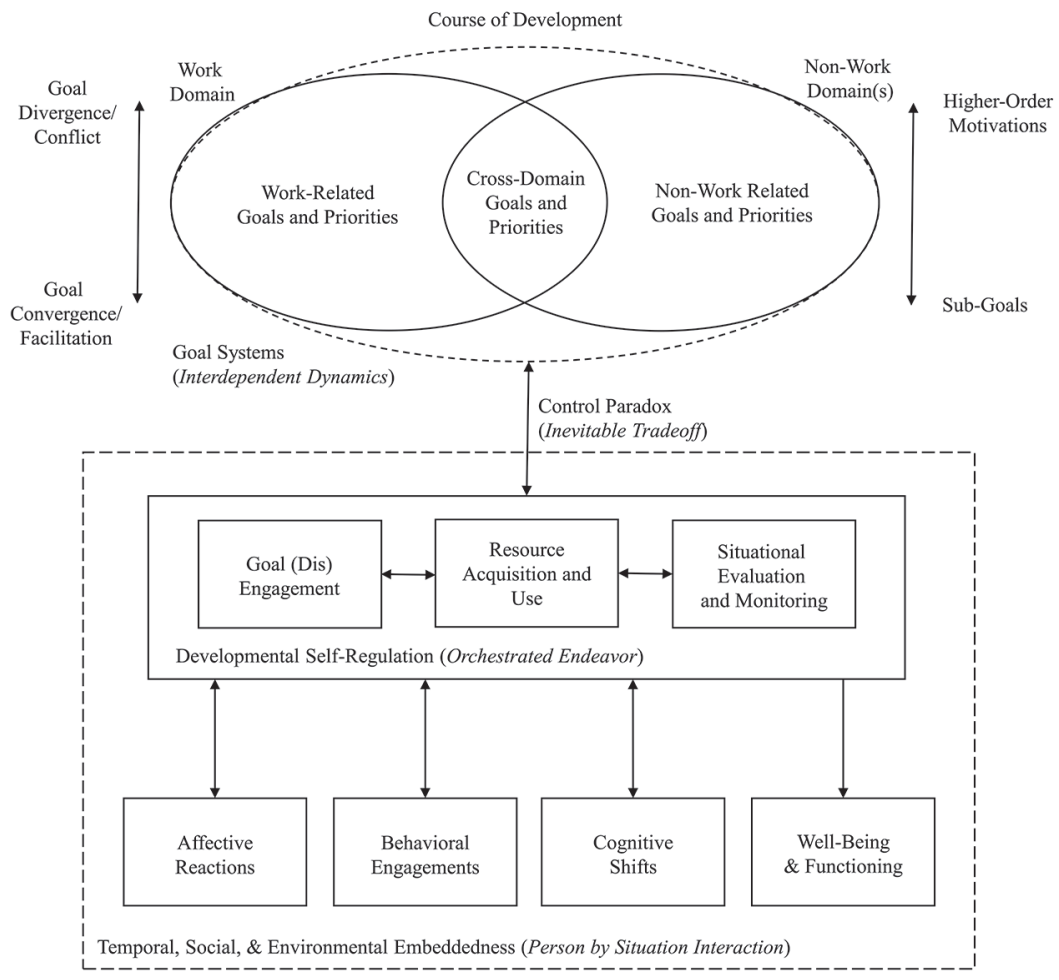

FIGURE 7.1 Integrated model of lifespan development theories 
reprioritization, etc.), (2) resource acquisition and use, and (3) situational evaluation and monitoring. In developmental self-regulatory theories, these classes are discussed in detail as either core constructs to measure directly (e.g., primary and secondary selective and compensatory control) or core functions of other theoretical mechanisms (e.g., goal (dis)engagement resulting from the process of socioemotional selectivity). In concert, individuals leverage these mechanisms to appraise themselves and their environment (i.e., with respect to resources and constraints and especially time and social influences), using this information in turn to engage in motivational efforts that will help them minimize losses and maximize gains as they age.

\section{Predictions}

The second section of our model pertains to the form and content of predictions, both theoretical and empirical in nature, from the lifespan perspective. These predictions are shared across theories or are complementary to one another, linking mechanisms to their most salient outcomes and relevant boundary conditions in and outside of the workplace. Specifically, across the theories, well-being and functioning are bolstered when an individual selects and strives toward goals that are congruent with their circumstances, needs, and abilities (e.g., person-environment fit). That is to say, the adaptiveness of certain goal pursuits and behaviors is contingent upon context, other domains, and other aspects of an individual's goal system. This suggests that, among other sources of variability, age differences will emerge both between- and within-person in the relative utility and impact of developmental self-regulation on outcomes.

Additionally, each theory makes predictions about functioning and well-being (e.g., subjective, psychological, physiological) as well as cognitive, affective, and behavioral consequences of certain mechanisms. For example, affect serves as a form of feedback in some theories, and different affective experiences, cognitive shifts (e.g., reappraisals), and behavioral engagements (e.g., seeking out new goal-relevant means) are implied to follow from strategy enactment. These, in turn, interact with and influence concurrent and future motivational strategy use; indeed, affect, cognition, and behavior serve as part of the self-regulatory process.

One important caveat and limitation of the current lifespan literature, especially as it is applied to the work context, must be noted. Specifically, holistic developmental self-regulation relative to one's life context is theoretically linked to well-being and effective functioning, not individual strategies measured as general tendencies (e.g., to engage vs. disengage from goals, in general) or their individual affective, behavioral, or cognitive outcroppings. The former entails consideration of developmental self-regulation as an orchestrated entity with well-being and functioning implications, while the latter tests these propositions in a more piecemeal and less theoretically consistent way. Still, this is how much of the literature assesses lifespan developmental concepts. This practice makes it 
seem, on the surface, that mechanisms can be adaptive in and of themselves, while theory would not suggest this is the case. This point will be discussed further with respect to measurement in our integration application section, but it is an important distinction that is frequently overlooked in the literature.

\section{Guiding Principles}

The third and final section of our model concerns the general principles that underlie the lifespan approach - principles that should similarly guide the study of age(ing) and work in the coming years. In other words, these principles provide context for research findings and should shape their interpretation and implications. Each of these principles aligns with the mechanisms and predictions just discussed but bear explicit mention here to emphasize their integrative importance. First, aside from the guiding principles of the lifespan development perspective discussed by P. B. Baltes (1987), each of these theories also features the fundamental roles that time and timing, context, social groups and influences, and various forms of feedback play in the process of development. Most broadly, this can be thought of as a "person by situation interaction" principle-one that highlights the situational, temporal, and social embeddedness of development, with various boundary conditions and processes of comparison and adjustment at play. Thus, while we discussed congruence in prediction earlier, this principle is more generally about the "situatedness" of all aspects of these models.

The remaining three principles featured in Figure 7.1 are (1) the inherent variability in and tradeoffs among intentionality, activity, and consciousness of regulation; (2) the existence of interconnected goal systems, with alignment (and conflict) across multiple levels, domains, and the course of development; and (c) the assumption that a latent entity of developmental self-regulation spans and underlies lifespan mechanisms. The "inevitable tradeoff" principle refers not only to the dually expansive (i.e., opportunities, gains) and limited (i.e., constraints, losses) nature of development but also to the varying ways and levels at which goal striving can be prompted (e.g., proactively vs. reactively) and how these by definition come at the expense of other goals. Indeed, acceptance of the prospect of control relinquishment in some areas so as to gain control in others-of the mutual exclusivities and paradoxes inherent to development (see Chapter 5 of this volume) - would seem to be a part of successful aging and control perception itself.

The "interdependent dynamics" principle is a natural offshoot of this idea, with individuals' goal selection and striving in a given domain (e.g., at work) existing within the larger motivational scope of their life: nonwork domains (e.g., family, leisure), needs, and priorities shift and intersect over time (see Chapter 16 of this volume), and goals exist at multiple levels of specificity and awareness (e.g., subgoals, higher-order motivations). Developmental self-regulation, which according to the "orchestrated endeavor" principle is a domain-and 
mechanism-spanning ability set, pervades and manages these various layers, optimizing convergence and synergy and minimizing divergence, resource waste, and conflict - in multiple senses - across the lifespan.

With our proposed integration introduced, we next present a discussion of predominant lifespan development theories. We focus on their areas of overlap, emphasizing our integration mechanisms, predictions, and principles in the process.

\section{Predominant Lifespan Development Theories}

Each of the specific lifespan theories reviewed next originated from the same metatheoretical lifespan development perspective. This broad perspective on human development treats aging as a continuous, modifiable, and lifelong process of stability and change: As individuals age, they experience both gains and losses within and across life domains, and they exert influence while also being embedded in a system of interacting contextual and developmental influences (P. B. Baltes, 1987).

\section{Developmental Self-Regulatory Theories}

The four theories comprising our first lifespan perspective category include Brandtstädter and Renner's (1990) dual-process model of assimilative and accommodative coping; P. B. Baltes and M. M. Baltes' (1990) model of selection, optimization, and compensation; Heckhausen et al's (2010) motivational theory of lifespan development; and Carstensen's $(1987,1991)$ socioemotional selectivity theory. These theories are broadly oriented, seeking to explain how individuals maintain well-being and functioning with age through adaptive goal selection and striving within and across life domains. The motivational mechanisms in this category of theories are largely conceptualized within and between individuals (see discussion of higher-level selection, optimization, and compensation, such as adaptation at the societal level in P. B. Baltes, 1997). Individuals developmentally self-regulate: That is, they leverage different motivational strategies, resulting in affective, behavioral, and cognitive changes or efforts, in the service of their priorities, resources, and opportunities. Through this process, they work to maximize gains and minimize losses as they age, such that gains can offset or even exceed losses.

In the dual-process model of assimilative and accommodative coping, motivational mechanisms take the form of two main constructs: tenacious goal pursuit (assimilative coping) and flexible goal adjustment (accommodative coping; Brandtstädter \& Renner, 1990). With tenacious goal pursuit, individuals actively adjust their capacities, circumstances, and resources to facilitate goal attainment through different behavioral engagements. Flexible goal adjustment, conversely, entails the adjustment of goals to fit an individual's (perceived) goal-relevant capacities, circumstances, and resources. 
Whether individuals initiate coping behaviors and which of these two coping methods an individual engages depends on goal-specific feedback processes and affective experiences. Individuals assess the magnitude of the "gap" between their current state and desired state (i.e., the product of goal attainment): The larger the perceived discrepancy, the more likely an individual will engage in coping behaviors. Moreover, which coping behaviors are engaged depends on various factors (e.g., goal challenge attributes, behavioral tendencies). If a discrepancy is perceived as manageable, individuals will initially leverage assimilative coping. If these efforts fail or if the discrepancy is perceived to be impractical and insurmountable, individuals will turn to accommodative coping tactics. These strategies are engaged in the service of maintaining self-consistency and congruence (i.e., between actual and goal states), which in turn bolsters well-being and functioning across the lifespan.

P. B. Baltes and M. M. Baltes' (1990) model of selection, optimization, and compensation, especially the prominent and related action-theory framework (Freund \& Baltes, 2000; Moghimi et al., 2017), presents a set of four developmental self-regulatory mechanisms that bear many similarities to other theories' constructs. These are elective and loss-based selection, optimization, and compensation. From an individual action regulation perspective (Freund \& P. B. Baltes, 2000), both elective and loss-based selection are goal-setting functions, wherein individuals identify and commit to "desired state" or "maintenance" goals, respectively. Optimization entails the acquisition and application of existing and available means for goal striving, and compensation entails the acquisition and application of alternative (i.e., new and/or previously untapped) means for goal striving.

Selection, optimization, and compensation are all treated as adaptive in a variety of combinations relative to the individual and their context. P. B. Baltes and M. M. Baltes (1990), for example, offer that individuals have unique mechanism "patterning, which may vary according to health, preferences, and resources. In each case of successful aging, there is likely to be a creative, individualized, and societally appropriate combination of selection, optimization, and compensation" (p. 24). These regulatory mechanisms are leveraged in the context of age-related gains and losses, with individuals working to maximize gains and minimize losses and thereby bolster their functioning and well-being. Freund and P. B. Baltes (2000) underline the importance of realistic and responsive regulatory feedback for (re)constructing and monitoring meaningful goal hierarchies, allocating resources to attainable goals, framing goals in positive affect-boosting terms, and monitoring the effectiveness of goal striving methods, among others.

Heckhausen and colleagues' (2010) motivational theory of lifespan development is a product of many years of theoretical revision and iteration (e.g., Heckhausen \& Schulz, 1993, 1995; Wrosch \& Heckhausen, 1999) and presents five core mechanisms: Selective and compensatory forms of primary and secondary control as well as a metaregulative optimization mechanism. 
Optimization refers to a cross domain regulatory function, through which individuals select goals that promote goal diversity, are congruent with opportunities and constraints, and stand to positively affect (or at least not interfere with) other current and future goals. After selecting goals, individuals use different control strategies for (dis)engagement. These fall into selective and compensatory categories, which entail efforts to change the external environment to support one's goals and efforts to change oneself to support goal striving in a given context, respectively.

The motivational theory of lifespan development presents two main challenges in development for which control mechanisms are relevant: Selectivity and compensation. Because individuals can only invest resources in some subset of goals at any given time, they must be selective in their allocation of resources to particular goals (e.g., those that are most meaningful and attainable). Individuals also face losses and challenges across the lifespan, for which they must compensate by adjusting priorities and buffering their sense of self. An individual's engagement of different control strategies - their efforts to strengthen goal commitment or to free resources for reallocation - is thus a product of balancing interests and abilities with limitations and gaps and is informed by regulatory feedback and affective experiences. When deadlines have passed and goals no longer seem tenable, for instance, goal disengagement is the adaptive option-just as accommodative coping was in the dual-process model.

The final developmental self-regulatory theory discussed in this chapter appears to be a departure from these tenets but, in fact, tends to the same theoretical space. Socioemotional selectivity theory (Carstensen, 1987, 1991; Carstensen et al., 1999) centers on the idea that people temporally self-contextualize their development, and this has an impact on the types of goals they select and strive toward. As individuals age, their perceptions of remaining opportunities, limitations, and time shift, transitioning from an expansive and open-ended orientation to a more restricted or constrained perspective. This perspective is referred to as future time perspective, which has most recently been described as possessing three dimensions: focus on opportunities, perceived remaining time, and focus on limitations (e.g., Rohr et al., 2017; Zacher, 2013).

Future time perspective serves as a mechanism for self-contextualizing regulatory decision-making and is contextually impactful. Having a realistic perception of opportunities, limitations, and time at one's disposal and striving toward goals congruent with these attributes is viewed as adaptive. Socioemotional selectivity theory predicts that the nature of these goals - specifically, their content and intended timing - will differ based upon an individual's future time perspective, with relatively older adults prioritizing shorter-term, emotionally meaningful goals, and relatively younger adults prioritizing longer-term, knowledge acquisition-related goals. Such goals, when aligned with perceived time, opportunities, and limitations, can enhance functioning and address the challenges of aging (i.e., anticipated and actual loss) as well as both proactively and reactively result 
in surprising improvements in emotional trajectories as adults age (Carstensen et al., 1999).

There is nuance to unpack regarding the adaptiveness of congruence between goals and an individual's personal, social, and temporal context, which is illuminative for our integration more generally. The model of selection, optimization, and compensation mentions the importance of orchestration and strategic balance in goal processes across levels, goals, and time, not just the appropriateness or frequency of an individual's strategy use relative to specific motivational pursuits. Both the motivational theory of lifespan development and the dual-process model emphasize holistic developmental regulation relative to multigoal systems, affective experiences, and an individual's sense of control and self, not simply how differential engagement or disengagement tactics aid in addressing particular objectives. Socioemotional selectivity theory, too, describes developmental self-regulation in terms of the balance or relative prioritization of different goal types, emotional regulation and functioning outcomes, and self-contextualization, rather than simply focusing on the utility of emotional versus instrumental goals or of open-ended versus constrained time perspective.

This means that having future time perspective and goals fit with one's circumstances is not only important to improve well-being and functioning on a goalby-goal basis but also that the nature of one's future time perspective is adaptive at a broader level, helping to reframe one's outlook, priorities (e.g., for desired and current selves or states), and perceived capacities as bearing opportunities rather than limitations. These are not theories focused on singular, intractable tensions between future preparedness and present emotional satisfaction (Lang \& Carstensen, 2002), goal engagement or disengagement, accommodative or assimilative coping, or selection, optimization, and compensation. Rather, they are theories about how these forces work together in complex and dynamic individual goal systems across development.

\section{Lifespan Emotion Regulation Theories}

There are two primary theories that relate developmental self-regulatory mechanisms to emotion regulation and age: Charles' (2010) strength and vulnerability integration model, and Urry and Gross' (2010) selection, optimization, and compensation with emotion regulation model. Both theories build upon the propositions discussed previously, translating socioemotional selectivity theory and the model of selection, optimization, and compensation into understanding affective experiences and functioning with age.

Charles' (2010) model is built upon socioemotional selectivity theory, as well as the integrality of time to emotional experiences and effective functioning across the lifespan. The core premise of the model is that individuals experience affective events and regulate emotions differently with age, which translates into distinct emotional trajectories associated with one's place in life. Specifically, 
based in socioemotional selectivity theory, relatively older adults experience distinct emotional benefits as a function of their temporal orientation, as well as the experience and knowledge that they have accumulated over their lifespan. Those adults who, in alignment with a more constrained future time perspective, focus more on present strengths and states also possess the ability to appraise their current life status favorably relative to goals and other individuals. Additionally, as a function of their greater emotional goal orientation, older adults benefit from smaller, more meaningful social networks that allow them to experience positive emotions, avoid negative emotions in the first place, and adapt to recognized loss. Still, they have vulnerabilities in certain situations where they cannot leverage appropriate regulatory tactics or down-regulate their physiological responses to stress.

Again, the themes of multiple domains and systems are pertinent to discuss, as these strategies and experiences must be considered within the broader scope of an individual's priorities, capacities, and challenges. Time, energy, and attention are limited resources. This means that different goals and strategies can facilitate or oppose one another, within and across domains. Charles' model underlines the idea that individuals' strengths and vulnerabilities, in regulating emotion and in regulating development more generally, are a product of and influence on other areas of their life. Some things become less "worth" the time and effort with age, and individuals can-figuratively and literally — not have the time to deal with some grievances that previously may have been more consequential. Regulatory efforts are shaped by the present and future as well as the past: Individuals deliberately cultivate social systems as they age, curating their experiences and developing areas of expertise and ability while eschewing others, and these influences accrue over time and persist in their effects.

Urry and Gross' (2010) expansion of the model of selection, optimization, and compensation to focus on emotion regulation seeks to explain similar phenomena regarding well-being and functioning with age. It parallels Baltes and colleagues' original model, applying each self-regulatory mechanism to emotional experiences. In particular, the model suggests that different forms of well-being (e.g., negative and positive affect, subjective well-being) improve with age as a result of enhanced emotion regulation. These emotion regulation improvements manifest in both emotion resource allocation increases, as well as more efficient and effective regulatory strategy usage (e.g., relative to the situation and available resources).

The model specifically proposes that adults select and optimize forms of emotion regulation (e.g., situation selection, attentional deployment) that compensate for age-related resource changes and losses, such as cognitive control deficits. As in its source model, compensatory strategies include resources that are gained or maintained with age: These include accrued resources such as close, intentional, meaningful social networks and situational knowledge (e.g., as in Charles', 2010, model) or pertain to sustained resources like response modulation capacity (i.e., emotional expression and experience control). 


\section{Applying the Lifespan Integration to Work: Implications and Recommendations}

We now turn our attention to a final matter: How can this integration be optimally applied to research on age(ing) and work? We have nine mechanism-, prediction-, and principle-relevant recommendations for implementing this integration and how it stands to impact research and practice (see Table 7.2).

\section{Mechanism Recommendations}

This integration should be used as a starting point for research on age(ing) and work among experienced and new scholars alike. It is challenging to assess the areas of commonality and divergence in this literature when referencing theory papers that largely do not converse with one another in a common, formalized vocabulary. Our chapter provides a guide to the fundamentals of each theory and the lifespan perspective that orient researchers toward the types of mechanisms and predictions they can (and should) make and the principles that contextualize a lifespan approach. We recommend greater standardization of language around these concepts in the age(ing) and work literature and greater consistency of conceptual representation and testing in research. One relatively straightforward application of this would be to consistently adopt the terminology presented herein (see Table 7.2).

In addition, we recommend that scholars refer to our model's key tenets, in their entirety, as they theorize, conduct research, and interpret their findings. Because this is a prescriptive integration, researchers still have much flexibility in their work while also coalescing toward semantic and structural standards that will ultimately codify research and practice. There are a number of disconnects, for example, between what lifespan theory would predict and what relationships are actually tested in research, and construct choices are often made out of convenience or atheoretical precedent. The majority of work studies leveraging the lifespan perspective either (1) use adapted lifespan theory to justify studies that do not involve or directly study lifespan mechanisms or (2) measure a subsample of lifespan mechanisms without using findings to further theory. To bridge this divide, there are a wealth of assumptions and principles that should be formally included in study designs (e.g., contextual boundary conditions) and interpretations of empirical findings (e.g., discussing the nature and source of possible underlying developmental self-regulatory ability). By continuing to omit (or reimagine) core aspects that structure, translate, and unite the lifespan perspective from studies in the work context, research risks misrepresenting the experience of the age-diverse workforce and misidentifying how best to support it.

\section{Prediction Recommendations}

In line with our focus on functioning and affect, behavior, and cognition predictions, our first prediction-relevant recommendation is to expand lifespan theory 
TABLE 7.2 Integrative Lifespan Terminology, Theories, Integrative Propositions, and Future Research Applications at Work

\begin{tabular}{|c|c|c|c|}
\hline Integrative Terminology & Example Theories and Concepts & Integrative Propositions & Selected Research Applications \\
\hline \multicolumn{4}{|l|}{ Mechanisms } \\
\hline $\begin{array}{l}\text { Goal (dis) } \\
\text { engagement }\end{array}$ & $\begin{array}{l}\text { MTLD: Selective and compensatory } \\
\text { primary and secondary control }\end{array}$ & $\begin{array}{l}\text { Developmental self-regulation is captured } \\
\text { by three categories of motivational }\end{array}$ & \multirow{3}{*}{$\begin{array}{l}\text { Standardize terminology } \\
\text { Refer to entire models and not just } \\
\text { to specific strategies in theorizing/ } \\
\text { hypothesis development, research } \\
\text { design and execution, and finding } \\
\text { interpretation }\end{array}$} \\
\hline $\begin{array}{l}\text { Resource acquisition } \\
\text { and use }\end{array}$ & SOC: Optimization, compensation & $\begin{array}{l}\text { processes, and these take the form of } \\
\text { core constructs to directly measure or }\end{array}$ & \\
\hline $\begin{array}{l}\text { Situational } \\
\text { evaluation and } \\
\text { monitoring }\end{array}$ & SST: Future time perspective & $\begin{array}{l}\text { are focal functions of other theoretical } \\
\text { processes }\end{array}$ & \\
\hline \multicolumn{4}{|l|}{ Predictions } \\
\hline $\begin{array}{l}\text { Well-being and } \\
\text { functioning }\end{array}$ & $\begin{array}{l}\text { AAC: Self-consistency and well- } \\
\text { being/functioning improvements } \\
\text { through realistic goal striving and } \\
\text { attainment }\end{array}$ & $\begin{array}{l}\text { Well-being and functioning are boosted } \\
\text { when an individual selects and strives } \\
\text { toward goals that are congruent with } \\
\text { their circumstances }\end{array}$ & \multirow{2}{*}{$\begin{array}{l}\text { Expand occupational health- and } \\
\text { emotion-focused research to examine } \\
\text { developmental self-regulation and } \\
\text { motivation in relation to stressor } \\
\text { appraisal and strain processes, coping } \\
\text { responses, and work design utility } \\
\text { Refine existing and create new measures } \\
\text { to accurately reflect mechanisms and } \\
\text { assumptions, including a shift toward } \\
\text { capturing affect, behaviors, and } \\
\text { cognition in lieu of general regulatory } \\
\text { tendencies }\end{array}$} \\
\hline $\begin{array}{l}\text { Affect, behavior, } \\
\text { cognition }\end{array}$ & $\begin{array}{l}\text { SOC-ER: Distinct, age-adaptive } \\
\text { emotion regulatory responses } \\
\text { in the form of cognition and } \\
\text { behavior } \\
\text { SAVI: Emotional well-being } \\
\text { advantages and vulnerabilities as a } \\
\text { product of past and present social } \\
\text { behaviors and cognitive appraisals }\end{array}$ & $\begin{array}{l}\text { Affective reactions, behavioral } \\
\text { engagements, and cognitive shifts are } \\
\text { implied to result from, interact with, } \\
\text { and influence concurrent and future } \\
\text { self-regulatory strategy enactment }\end{array}$ & \\
\hline
\end{tabular}

(Continued) 
TABLE 7.2 (Continued)

\begin{tabular}{|c|c|c|c|}
\hline Integrative Terminology & Example Theories and Concepts & Integrative Propositions & Selected Research Applications \\
\hline \multicolumn{4}{|l|}{ Guiding Principles } \\
\hline $\begin{array}{l}\text { Person by situation } \\
\text { interaction }\end{array}$ & $\begin{array}{l}\text { SST: Self-contextualization of } \\
\text { development as a function of } \\
\text { perceived time and corresponding } \\
\text { socioemotional priorities }\end{array}$ & $\begin{array}{l}\text { Development is situationally, temporally, } \\
\text { and socially embedded, with various } \\
\text { boundary conditions and processes of } \\
\text { comparison and adjustment at play }\end{array}$ & $\begin{array}{l}\text { Consider intersections of work } \\
\text { motivation and lifespan theories } \\
\text { (vocational decision-making, goal } \\
\text { timing and discounting) }\end{array}$ \\
\hline Inevitable trade-off & $\begin{array}{l}\text { AAC: Recursive patterns of losses/ } \\
\text { failures and gains/successes that } \\
\text { shape individual agency and } \\
\text { functioning, reactively and/or } \\
\text { proactively }\end{array}$ & $\begin{array}{l}\text { Aging is defined by both opportunities } \\
\text { and constraints, and individuals must } \\
\text { relinquish control or goals in some } \\
\text { areas in order to gain control and strive } \\
\text { toward goals in others }\end{array}$ & $\begin{array}{l}\text { Study multidomain influences on work } \\
\text { motivation, especially pertaining } \\
\text { to multiple goal systems, temporal } \\
\text { perceptions (e.g., deadlines, urgency), } \\
\text { and social influences (e.g., feedback, }\end{array}$ \\
\hline $\begin{array}{l}\text { Interdependent } \\
\text { dynamics }\end{array}$ & $\begin{array}{l}\text { SOC: Individuals construct and } \\
\text { monitor goal hierarchies, allocating } \\
\text { resources to goals within an } \\
\text { individualized context }\end{array}$ & $\begin{array}{l}\text { Goals exist in the broader motivational } \\
\text { context of individuals' lives, with } \\
\text { alignment and conflict across } \\
\text { levels, domains, and the course of } \\
\text { development }\end{array}$ & $\begin{array}{l}\text { normative societal standards, nonwork } \\
\text { forces) } \\
\text { Investigate how individuals appraise } \\
\text { various types of "fit" and their age- } \\
\text { contingent effects }\end{array}$ \\
\hline $\begin{array}{l}\text { Orchestrated } \\
\text { endeavor }\end{array}$ & $\begin{array}{l}\text { MTLD: Goal processes are meta- } \\
\text { regulated through optimization, } \\
\text { whereby individuals choose and } \\
\text { schedule motivational pursuits } \\
\text { geared for success with respect to } \\
\text { time, opportunities, and control } \\
\text { costs and benefits }\end{array}$ & $\begin{array}{l}\text { Mechanisms do not function in isolation } \\
\text { but exist as part of a domain- and } \\
\text { mechanism-spanning ability set } \\
\text { (developmental self-regulation), } \\
\text { optimizing motivational convergence } \\
\text { and synergy and minimizing divergence, } \\
\text { resource waste, and conflict-in } \\
\text { multiple senses-across the lifespan. }\end{array}$ & $\begin{array}{l}\text { Apply principles (as well as mechanisms } \\
\text { and predictions) at the within- } \\
\text { domain level (e.g., socialization and } \\
\text { relationship cultivation within a work } \\
\text { role, leadership development) } \\
\text { Investigate the existence of a general } \\
\text { factor of developmental self-regulation } \\
\text { and develop a single measure of this as } \\
\text { appropriate }\end{array}$ \\
\hline
\end{tabular}

Note: "AAC" = dual-process model of assimilative and accommodative coping. "MTLD" = the motivational theory of lifespan development. "SOC" = the model of selection, optimization, and compensation. "SST" = socioemotional selectivity theory. "SAVI" = the strength and vulnerability integration model. "SOC-ER" = the model of selection, optimization, and compensation with emotion regulation 
applications and research in the areas of occupational health and emotion regulation at work. Health is often a focal component of studies of age(ing) and work, yet this does not mean that theories of occupational health and emotional demands at work have been integrated with lifespan theories. Past work has drawn on work such as job demands-resources theory (e.g., Liebermann et al., 2013; Sonnega et al., 2018) or the emotional labor literature (e.g., Dahling \& Perez, 2010; Toomey et al., 2020). However, more formal incorporation of the motivational underpinnings of lifespan development into workplace health promotion and maintenance, as well as emotion regulation and well-being, is needed.

The mechanisms, predictions, and principles presented in this chapter can readily be applied to health- and emotion-focused research. This could be accomplished in line with the selection, optimization, and compensation in emotion regulation and strength and vulnerabilities integration models. New integrative conceptualizations, such as advances in theory and research on health and stress monitoring or socioemotional feedback processes in relationships and interactions, could be beneficial as well. There are many important points to investigate therefrom, including how lifespan developmental self-regulatory processes may intercede upon or interact with stressor appraisal processes, strain outcomes, coping responses, the work-life interface, and the desirability and impact of certain work design features on aging employees' health.

Second and relatedly, our integration has important implications and applications to how aging-relevant constructs are measured in the work context: in particular, developmental self-regulatory mechanisms and "successful aging" outcomes. Issues with predominant developmental self-regulatory measurement tools have been noted in past work (e.g., unreliability, inconsistent usage and factor structures; Rudolph, 2016), and study paradigms rely almost exclusively on selfreport measures that ask individuals about their domain-general or workplacespecific motivational and behavioral tendencies (see Chapter 8 of this volume). These present notable limitations to research findings, which we recommend be addressed through scale revisions and alternative measurement approaches (e.g., capturing affect, behaviors, and cognition). Aside from the "what," "how" constructs are measured will also need to be addressed: Alternative paradigms and measurement methods are advisable, including other-report, experimental, and varying time-scale designs for capturing self-regulatory behaviors and perceptions (see Chapters 10 and 11 of this volume).

\section{Guiding Principles}

In line with our guiding principles, a few remaining research recommendations can be made. First, our integration highlights the need for more work on where prominent theories of work motivation intersect with and inform lifespan development theories, including work concerning vocational decision-making and retirement intentions, control beliefs, identity and needs, goal timing and 
discounting, and differential goal strategy engagement. Second, attention to multidomain influences on work motivation is needed. In particular, much stands to be learned about individuals' experiences and behaviors within multi-goal systems that are temporally bound and both socially influenced and constructed. This perspective is in contrast to three common but incomplete approaches used at present: (1) viewing workplace decisions of aging workers in isolation from other intersecting life spheres, (2) treating decisions as a pure function of personal, age-related gains and losses or structural aspects of one's job, or (3) assuming that goal-directed behavioral tendencies necessarily apply across domains and goals rather than having more context- and goal-specific effects.

As such, there are potentially fruitful syntheses to be had between lifespan developmental concepts and work on multiple goal systems in the work psychology and motivation literatures. Efforts in these areas will lead to more informative nuance around employee life management and success with age. More work on aspects of regulation as they relate to employees could prove useful as well. In particular, continued research on sources of feedback (e.g., informal and formal performance feedback, goal discrepancy judgements and processes) as well as deadline setting and effects (e.g., work task and career timing, subjective experiences of time pressure and urgency) in relation to aging employees and motivation would move the field forward (see also Dello Russo et al., 2017; Tang et al., 2020; Wang et al., 2015).

Third, we recommend more research on individual by context interactions and development over time. "Fit" was discussed throughout this chapter as a component of developmental self-regulation (e.g., person-environment, uncertainty congruence, goal and resource matching), and it has been studied with respect to age and well-being outcomes in recent years (see Krumm et al., 2013; Rauvola et al., 2020; Zacher et al., 2014). Our integration highlights the need for more work on both how individuals of different ages appraise various types of "fit" and how these fit perceptions may have age- or other identity-contingent effects on outcomes of interest. Given the influence of context on developmental selfregulation, social partners may shape or factor into the "fitting" process as well, which bears more exploration (e.g., the idea of "co-developing individuals"; Baltes, 1987, p. 621; see also Salmela-Aro, 2009).

More generally, although much research tends to focus its applications toward relatively older or younger employees, our fourth recommendation is to consider age and developmental processes across a complete continuum. Research must prioritize the needs of employees of all ages, and lifespan mechanisms, predictions, and principles could be applied to within-context "aging" and development. For example, leadership development, socialization, and relationship growth within one's organizational "lifespan" and gain and loss cycles as one matures in a given role or set of roles could be fruitful areas for integration and innovation. Outside of measurement modifications to concern the work domain specifically (e.g., 
occupational future time perspective, Zacher \& Frese, 2009), such principles have not been extended in this way (see also Chapter 9 of this volume).

Finally, our integration highlights a number of fundamental overlaps across lifespan development theories, as well as the potential for these theories to share an underlying regulatory ability. The potential existence of a general factor of developmental self-regulation should be investigated to this end, which would help theoretically and operationally represent and further integrate mechanisms into the "orchestrated endeavor" within which they operate. Based on this, research should explore whether a single measure of developmental self-regulation can be developed (e.g., representing the three main mechanism categories above). This could be used alongside refined and multidomain versions of other scales and theoretical components (e.g., time perspective, affective reactions, cognitive shifts, behavioral engagements) recommended earlier.

\section{Conclusion}

Lifespan perspectives comprise a large share of the age(ing) and work literature, and there is no shortage of theory to draw upon in this area of research. At the same time, however, it can prove difficult to differentiate or select between these theories, as well as to holistically interpret the body of research based upon them. The present chapter sought to highlight the shared aspects of predominant theories of lifespan development and to propose a conceptual integration of these perspectives, particularly so as to pave a path toward synthesis and utility. It is our hope that the components highlighted in our chapter give new and experienced scholars alike new ways to engage in "lifespan thinking," through more attention to the commonalities spanning lifespan mechanisms, predictions, and guiding principles as well as these parallel aspects of the work context. In this way, the field can move closer to an understanding of how individuals age successfully, recognizing the commonalities and distinctions across theories as well as the populations whose development and functioning they seek to describe.

\section{References}

Baltes, P. B. (1987). Theoretical propositions of life-span developmental psychology: On the dynamics between growth and decline. Developmental Psychology, 23, 611-626. doi:10.1037/0012-1649.23.5.611

Baltes, P. B. (1997). On the incomplete architecture of human ontogeny: Selection, optimization, and compensation as foundation of developmental theory. American Psychologist, 52, 366-380. doi:10.1037/0003-066x.52.4.366

Baltes, P. B., \& Baltes, M. M. (1990). Psychological perspectives on successful aging: The model of selective optimization with compensation. In P. B. Baltes \& M. M. Baltes (Eds.), Successful aging: Perspectives from the behavioral sciences (pp. 1-34). Cambridge University Press. 
Baltes, P. B., Baltes, M. M., Freund, A. M., \& Lang, F. (1999). The measurement of selection, optimization, and compensation (SOC) by self report. Max Planck Institute for Human Development.

Brandtstädter, J., \& Renner, G. (1990). Tenacious goal pursuit and flexible goal adjustment: Explication and age-related analysis of assimilative and accommodative strategies of coping. Psychology and Aging, 5, 58-67. doi:10.1037/0882-7974.5.1.58

Carstensen, L. L. (1987). Age-related changes in social activity. In L. L. Carstensen \& B. A. Edelstein (Eds.), Handbook of clinical gerontology (pp. 222-237). Pergamon Press.

Carstensen, L. L. (1991). Socioemotional selectivity theory: Social activity in life-span context. In K. W. Schaie (Ed.), Annual review of gerontology \& geriatrics (Vol. 11, pp. 195217). Springer.

Carstensen, L. L., Isaacowitz, D. M., \& Charles, S. T. (1999). Taking time seriously: A theory of socioemotional selectivity. American Psychologist, 54, 165-181. doi:10.1037/0003-066x.54.3.165

Carstensen, L. L., \& Lang, F. R. (1996). Future time perspective scale. Stanford University Press.

Charles, S. T. (2010). Strength and vulnerability integration (SAVI): A model of emotional well-being across adulthood. Psychological Bulletin, 136, 1068-1091. doi:10.1037/ a0021232

Dahling, J. J., \& Perez, L. A. (2010). Older worker, different actor? Linking age and emotional labor strategies. Personality and Individual Differences, 48, 574-578. doi:10.1016/j. paid.2009.12.009

Dello Russo, S., Miraglia, M., \& Borgogni, L. (2017). Reducing organizational politics in performance appraisal: The role of coaching leaders for age-diverse employees. Human Resource Management, 56, 769-783. doi:10.1002/hrm.21799

Freund, A. M., \& Baltes, P. B. (2000). The orchestration of selection, optimization and compensation: An action-theoretical conceptualization of a theory of developmental regulation. In W. J. Perrig \& A. Grob (Eds.), Control of human behavior, mental processes, and consciousness (pp. 35-58). Lawrance Erlbaum \& Associates.

Heckhausen, J., \& Schulz, R. (1993). Optimization by selection and compensation: Balancing primary and secondary control in life span development. International Journal of Behavioral Development, 16, 287-303. doi:10.1177/016502549301600210

Heckhausen, J., \& Schulz, R. (1995). A life-span theory of control. Psychological Review, 102, 284-304. doi:10.1037/0033-295x.102.2.284

Heckhausen, J., Schulz, R., \& Wrosch, C. (1998). Developmental regulation in adulthood: Optimization in primary and secondary control-A multiscale questionnaire (OPS-Scales). Max Planck Institute for Human Development.

Heckhausen, J., Wrosch, C., \& Schulz, R. (2010). A motivational theory of life-span development. Psychological Review, 117, 32-60. doi:10.1037/a0017668

Krumm, S., Grube, A., \& Hertel, G. (2013). No time for compromises: Age as a moderator of the relation between needs-supply fit and job satisfaction. European Journal of Work and Organizational Psychology, 22, 547-562. doi:10.1080/1359432X.2012.676248

Lang, F. R., \& Carstensen, L. L. (2002). Time counts: Future time perspective, goals, and social relationships. Psychology and Aging, 17, 125-139. doi:10.1037/0882-7974.17.1.125

Liebermann, S. C., Wegge, J., \& Müller, A. (2013). Drivers of the expectation of remaining in the same job until retirement age: A working life span demands-resources model. European Journal of Work and Organizational Psychology, 22, 347-361. doi:10.10 80/1359432X.2012.753878 
Moghimi, D., Zacher, H., Scheibe, S., \& Van Yperen, N. W. (2017). The selection, optimization, and compensation model in the work context: A systematic review and meta-analysis of two decades of research. Journal of Organizational Behavior, 38, 247275. doi:10.1002/job.2108

Rauvola, R. S., Rudolph, C. W., Ebbert, L. K., \& Zacher, H. (2020). Person-environment fit and work satisfaction: Exploring the conditional effects of age. Work, Aging and Retirement, 6, 101-117. doi:10.1093/workar/waz011

Rohr, M. K., John, D. T., Fung, H. H., \& Lang, F. R. (2017). A three-component model of future time perspective across adulthood. Psychology and Aging, 32, 597-607. doi:10.1037/pag0000191

Rudolph, C. W. (2016). Lifespan developmental perspectives on working: A literature review of motivational theories. Work, Aging and Retirement, 2, 130-158. doi:10.1093/ workar/waw012

Salmela-Aro, K. (2009). Personal goals and well-being during critical life transitions: The four C's-Channelling, choice, co-agency and compensation. Advances in Life Course Research, 14, 63-73. doi:10.1016/j.alcr.2009.03.003

Sonnega, A., Helppie-McFall, B., Hudomiet, P., Willis, R. J., \& Fisher, G. G. (2018). A comparison of subjective and objective job demands and fit with personal resources as predictors of retirement timing in a national US sample. Work, Aging and Retirement, 4, 37-51. doi:10.1093/workar/wax016

Tang, S., Richter, A. W., \& Nadkarni, S. (2020). Subjective time in organizations: Conceptual clarification, integration, and implications for future research. Journal of Organizational Behavior, 41, 210-234. doi:10.1002/job.2421

Toomey, E. C., Rudolph, C. W., \& Zacher, H. (2020). Age-conditional effects of political skill and empathy on emotional labor: An experience sampling study. Work, Aging and Retirement, 7, 46-60. doi:10.1093/workar/waaa004

Urry, H. L., \& Gross, J. J. (2010). Emotion regulation in older age. Current Directions in Psychological Science, 19, 352-357. doi:10.1177/0963721410388395

Wang, M., Burlacu, G., Truxillo, D., James, K., \& Yao, X. (2015). Age differences in feedback reactions: The roles of employee feedback orientation on social awareness and utility. Journal of Applied Psychology, 100, 1296-1308. doi:10.1037/a0038334

Wrosch, C., \& Heckhausen, J. (1999). Control processes before and after passing a developmental deadline: Activation and deactivation of intimate relationship goals. Journal of Personality and Social Psychology, 77, 415-427. doi:10.1037/0022-3514.77.2.415

Zacher, H. (2013). Older job seekers' job search intensity: The interplay of proactive personality, age and occupational future time perspective. Ageing \& Society, 33, 1139-1166. doi:10.1017/S0144686X12000451

Zacher, H., Feldman, D. C., \& Schulz, H. (2014). Age, occupational strain, and wellbeing: A person-environment fit perspective. In P. L. Perrewé, C. C. Rosen, \& J. R. B. Halbesleben (Eds.), The role of demographics in occupational health and well being (pp. 83-111). Emerald Group Publishing. doi:10.1108/S1479-355520140000012002

Zacher, H., \& Frese, M. (2009). Remaining time and opportunities at work: Relationships between age, work characteristics, and occupational future time perspective. Psychology and Aging, 24, 487-493. doi:10.1037/a0015425 